\title{
Zirconia nanotube coatings - UV-resistant superhydrophobic surfaces
}

Swathi Naidu Vakamulla Raghu ${ }^{a, b}$, Khajidkhand Chuluunbandi ${ }^{a}$, Manuela Sonja Killian ${ }^{a, b *}$

(a) Department of Materials Science, Institute for Surface Science and Corrosion (LKO), Friedrich-Alexander-University of Erlangen-Nuremberg, Martensstrasse 7, 91058 Erlangen, Germany

(b) Chemistry and Structure of Novel Materials, University of Siegen, Paul-Bonatz-Str. 9-11, 57076 Siegen, Germany

E-mail: Manuela.Killian@uni-siegen.de

Keywords: Optical coatings, self-assembled monolayer (SAM), ToF-SIMS, XPS zirconia, anodization, nanostructure, superhydrophobicity, self-cleaning

Abstract: Surface modifications influence material interactions such as wettability, imparting hydrophobicity or hydrophilicity. Mainstream research focused on enhancing product shelf-life, directs attention towards superhydrophobic surfaces (SHS). SHS offer several benefits for outdoor applications such as self-cleaning, anti-soiling, anti-mist etc. In this manuscript, we explore the possibility of combining structural and chemical modifications to metal substrates in order to create superhydrophobic metal oxide surfaces. $\mathrm{ZrO}_{2}$-nanotubes are evaluated with regard to their application as transparent UV-stable superhydrophobic coatings. Nanostructured oxide surfaces are created via single-step electrochemical anodization. The absence of HF acid-based pre-etching steps offer a safe and alternatively a green synthesis route. Anodized oxides are modified using octadecylphosphonic acid self-assembled monolayers, demonstrate superhydrophobicity and are evaluated for their mechanical stability under a jet of water, chemical stability under indirect sunlight irradiation in air/water and direct UV exposure. Zirconia nanotubular films were evaluated for optical transparency using light microscopy and surface wettability of the different 
zirconia-composites was compared to the model system-titania. Structural and compositional differences of the SAM layer upon time dependent decay were analyzed with X-ray photoelectron spectroscopy.

\section{Introduction}

Surface modifications have been widely employed in materials as a means of pre-treatment and in some cases as the final step that offers the required functionality. Passivating surfaces via electrochemical anodization can create micro- to nanostructured oxide layers.[1][2] Tailoring material surfaces can influence subsequent interactions such as the wetting behavior. Surface wettability plays a vital role in developing super-hydrophobic surfaces (SHS). SHS surfaces are of interest due to their self-cleaning properties owing to their high contact angle $>150^{\circ}$ resulting in non-wetting behavior and are ideal for outdoor applications that require little to no interaction with ambient environmental conditions. Titania nanostructures have garnered significant interest owing to their multifaceted attributes and researchers have successfully created SHS on anodized titania by hydrophobization.[3][4][5] Titania is reported to have photocatalytic properties allowing for efficient decomposition/degradation reactions.[6] However, this feature works against SAM coated titania optical systems, especially for outdoor applications as it is susceptible to increased degradation. In light of this situation, it would be advantageous to have a material that is not as photocatalytically 'active', but offers comparable or superior SHS properties. Zirconia is a valve metal belonging to the group IV- Titania family and having a wide band gap in the range of 5-7 eV, resulting in lower absorption in certain spectral regions.[1][2] Zirconia offers impressive electrical, optical, chemical and mechanical properties.[7][8][9] Metal-oxide nanostructures such as $\mathrm{ZrO}_{2}$ can be synthesized via electrochemical anodization involving the systematic growth and dissolution of metal-oxide layers in the presence of an electrolyte in an 
electrochemical cell. Organic electrolytes promise a high degree of self-ordering in this process and often require a harsh hydrofluoric (HF) acid pre-etching step in order to produce well-ordered nanoporous structures. In this work, we produce distinct, highly-ordered and stable nanotube arrays using a modified variation of the fluoride based organic electrolyte as prepared in Amer et al.[10] The possibility of creating nanostructures in a single step process without the use of a strong HF acid pre-etching step makes this a relatively less toxic/hazardous, more user and environmentally friendly practice whilst being strongly reproducible.

Zirconia nanostructures have potential applications in the field of catalyst production, electrodes, fuel cells and more recently as bio-ceramic implants owing to their non-toxic nature and ability to promote cell growth.[8][11][12] Anodized $\mathrm{ZrO}_{2}$ substrates have high surface energies and tend to promote enhanced adhesion/binding of thin organic films on the metal oxide surface capable of eliciting different surface behavior.[13] Spontaneously forming SAMs can readily modify surfaces into SHS and have been extensively researched and developed for a myriad of applications ranging from anti-fog coatings, anti-dirt/freeze, drag reducing surfaces to antibacterial biomedical surface modifications.[14][15][16][17][18] SHS in addition to self-cleaning behavior, enhance the shelf life and prolong functionality of the underlying working surfaces. Many techniques have been developed in order to form effective SHS via SAM functionalization. SAMs can be produced on oxide surfaces, e.g., through PVD, electro-deposition, micro-contact printing and the more commonly used immersion in bulk solution.[15][19][20][21] The prerequisites while choosing SAM molecules for the purpose of creating SHS on zirconia are strong binding affinity and integrity of the single layer coverage. Phosphonate head groups have been reported to easily attach to a wide range of oxide surfaces including $\mathrm{ZrO}_{2}$.[22][23][24][25] Gawalt et al. investigated the adsorption of octadecylphosphonic acid $\left(\mathrm{CH}_{3}\left(\mathrm{CH}_{2}\right)_{17} \mathrm{PO}_{3} \mathrm{H}_{2}\right.$, OPA) 
on titania, the same was further pursued for other metal oxide surfaces and Gao et al.[24][26] reported that phosphonic acids react strongly with $\mathrm{ZrO}_{2}$. Reaction mechanism suggests, binding occurs at the interface via P-O-M (M is for metal) bond formation. Metal oxides are terminated with surface hydroxyl groups $(\mathrm{M}-\mathrm{OH})$ and as a result of condensation reactions with phosphonic acid groups (P-OH), form P-O-M bonds, imparting a covalent bond formation.

Chang et al. mention the possibility of using $\mathrm{ZrO}_{2}$ in the fabrication of transparent optical devices.[27] It has a niche application area as optical coating as it is a high index material that can be used from near-UV to mid-IR range. Composites made of $\mathrm{ZrO}_{2}$ coated with OPA selfassembled monolayers (SAMs) may be capable of acting as optically clear super-hydrophobic coatings, which could be interesting, e.g., for solar cell or window coatings.

The present work investigates the fabrication of $\mathrm{ZrO}_{2}$ structures consisting of compact oxide and nanotubular oxides. The morphology of these oxide surfaces was characterized using SEM and XRD. In addition to anodization procedures, the integrity of OPA SAMs on amorphous zirconia and titania (as a reference material) will be extensively analyzed. Emphasis is placed on the monolayer stability upon ambient as well as water-immersed, sunlight exposure and UV light irradiation. (Super-)hydrophobicity was assessed as a measure of wettability of the composite surfaces using water droplets via sessile drop contact angle measurements. The mechanical stability of the OPA SAM under a continuous water jet was also assessed as a function of decreasing hydrophobicity. Surface analysis furthermore was performed via ToF-SIMS and XPS.

\section{RESULTS AND DISCUSSION}

When $\mathrm{Zr}$ is anodized under appropriate conditions in an organic electrolyte, a resulting oxide film showing uniform nanotube arrays can be achieved as represented in Figure 1. (Anodization of zirconia: SEM micrographs - (a) anodized $\mathrm{ZrO}_{2}$ top, (b) anodized $\mathrm{ZrO}_{2}$ cross-section and $\mathrm{ZrO}_{2}$ 
XRD (inset)). The SEM micrographs depict circular morphology of the individual $\mathrm{ZrO}_{2}$ nanotubes and an average layer thickness of $9 \mu \mathrm{m}$ obtained after $30 \mathrm{~min}$ of anodization. The structural integrity of the coatings formed in the absence of pretreatment step(s) as reported in this work are comparable to those reported for samples undergoing pre-treatment requiring immersion in HFcontaining solutions. This growth model although identical in morphology to previously reported morphologies, in reality reports on improved production quality while minimizing fabrication duration and fabrication hazards.[28][29][30] The oxide layers formed are thick, continuous and robust on all geometries of substrate materials investigated. Figure 1. ((b)-inset) shows X-ray diffraction (XRD) analysis of the $\mathrm{ZrO}_{2}$ nanostructures. The as-anodized samples consist of amorphous $\mathrm{ZrO}_{2}$ nanotube arrays as the signals appearing at $35^{\circ}(002), 37^{\circ}(101), 48^{\circ}(102)$ and $64^{\circ}$ (003) are characteristic facets of $\mathrm{Zr}$ metal, which is the substrate in this case.[31][32] The coatings are transparent to more than $80 \%$ of white light (cf. Supporting information Figure S5.) The nanostructured $\mathrm{ZrO}_{2}$ layers were rendered hydrophobic by adsorption of a SAM of OPA molecules, a long chain aliphatic phosphonic acid. The hydrophobicity of the layer depends on the extent and quality of P-O-M bond formation. These bonds elicit strong binding forces due to the coordination of phosphoryl oxygen to the Lewis acidic sites on the surface. It is expected that alkane phosphonic acid densely packed films assemble as a result of hydrogen-bonding between the head groups along with Van der Waals interaction with the methyl units.[26] Phosphonic acids were previously shown to form stable bonds to $\mathrm{ZrO}_{2}$.[24] Additionally, surface energy, topography and homogeneity also play a crucial role in influencing the hydrophobicity. Functionalized nanostructured surfaces reportedly trap larger volumes of air within their asperities in order to stabilize the Cassie-Baxter state responsible for the super hydrophobicity as depicted in Figure 2 a. (Schematic- Cassie-Baxter model)[33]. Native oxide is the air formed oxide layer 
present on the as-received (and cleaned) $\mathrm{Zr}$ foil.[30] Compact oxide (SEM image can be found in Figure S1) and nanotubular $\mathrm{ZrO}_{2}$ were obtained by anodization. The controlled formation of anodic oxide layers shows a clear improvement in hydrophilicity, cf. Figure 2b (Comparison of surface hydrophobicity pre and post modification with ODPA SAMs on anodized $\mathrm{ZrO}_{2}$ ), which indicates an improved oxide quality and purity of the anodic layers. Due to the increased surface area, the nanostructure permits fluid infiltration and consequently enhances wetting. Post SAM functionalization, only a moderate increase in hydrophobicity $\left(35^{\circ}\right.$ to $\left.75^{\circ} \pm 3^{\circ}\right)$ is observed for native $\mathrm{ZrO}_{2}$ whilst the compact oxide shows a clear enhancement in contact angle $\left(17^{\circ}\right.$ to $140^{\circ} \pm$ $2^{\circ}$ ), as shown in Figure $2 \mathrm{~b}$. The nanotubular $\mathrm{ZrO}_{2}$ can even be switched from superhydrophilic $\left(0^{\circ}\right)$ to superhydrophobic $\left(155^{\circ} \pm 5^{\circ}\right)$ upon simple immersion in an OPA solution. The tube length did not influence the hydrophobic nature of the coating. [34] Additionally, the presence of the OPA- SAM was confirmed via ToF-SIMS and the spectrum can be found (cf. Supporting Information, Figure S2). We conclude that OPA forms a superhydrophobic self-assembled monolayer on zirconia nanotubes.

In this work, we test 'OPA - SAM based SHS ZrNT' composite as UV-stable superhydrophobic coatings. The intended use of the material is to function as an optically clear self-cleaning surface, which may improve longevity of any underlying working surface, e.g. in outdoor solar cells under irradiated conditions. Sunlight consists of three major components, visible light, ultraviolet light (UV) and infrared radiation (IR). UV light components that can potentially influence within the earth's atmosphere are further split into long wave UVA $(315-400 \mathrm{~nm})$ and short wave UVB (280- $315 \mathrm{~nm}$ ). UVA light makes up a larger portion and penetrates deeper. In order to test the stability of the composite systems, the first experimental setup involves indirect irradiation (ambient and water-immersed) wherein samples are subjected to UVA light only, as clear glass 
(windows and containers) that are transparent to visible light absorb nearly all UVB.[35][36] Triplicate sample sets were assembled onto a windowpane with the SAM face-side towards the window, exposed for a period of up to 50 days. The SAM stability was evaluated by contact angle measurements after 1, 5, 14, 21 and 50 days. Figure 3 (Wettability measurements of OPA modified $\mathrm{ZrO}_{2}$ nanotubes upon sunlight exposure in air (Contact angle versus Time)) shows the change in hydrophobicity with respect to the exposure time. Zirconia nanotubes have an initial contact angle well above $160^{\circ} \pm 2^{\circ}$; the water droplets kept rolling off the surface and actually could only be measured on defective sites of the material (cf. Supporting Information, Figure S3). As a reference material, commonly used nanostructured titania was used as represented in (cf. Supporting Information, Figure S4). In comparison, the titania nanotube samples show superhydrophobicity at $\left(156^{\circ} \pm 2^{\circ}\right)$ on day zero. The slightly lower value may be indicative of a slightly lower initial coverage density of OPA molecules. Both ZrNT and TiNT show a similar rapidly decreasing trend in hydrophobicity with an average decrease of $\left(15 \pm 3^{\circ}\right)$ in contact angle measurements within the first 5 days after synthesis. A possible explanation for this behavior could be attributed to the reversible nature of condensation reactions. This could imply that repeated contact angle measurements can result in dissolution of OPA from investigated regions, exposing the underlying substrate and subsequently making it permeable to more water molecules. Alternatively, If the OPA coverage is not ideally dense packed, molecules may be attached in random, partially folded orientations and an unfolding of the chain may result in surface exposure. The contact angle decay measured in air is apparent when comparing the values of day 0 and day $50, \operatorname{ZrNT}\left(>160^{\circ} \rightarrow 145 \pm 2^{\circ}\right), \operatorname{TiNT}\left(156^{\circ} \rightarrow 127^{\circ} \pm 2^{\circ}\right), \operatorname{ZrCO}\left(140^{\circ} \rightarrow 116^{\circ} \pm 2^{\circ}\right)$ and $\operatorname{TiCO}\left(130^{\circ}\right.$ $\left.\rightarrow 40^{\circ} \pm 3^{\circ}\right)$. ZrNT samples stored under ambient conditions in the dark for a period of 50 days show similar stability to their irradiated counterparts, i.e. they maintain hydrophobic behavior and 
a contact angle of $145 \pm 3^{\circ}$ on day 50 was recorded. This indicates that the observed decrease in contact angle probably is induced by the measurement itself and not by the irradiation conditions. Zirconia compact oxide even shows a comparable behavior to titania nanotubes and this indicates towards zirconia's superior bond strength and packing density with OPA molecules. The TiCO samples show a much faster linear decay rate throughout the 50-day period. It is interesting to see a stabilization of contact angle after 14 days for both zirconia nanostructure and compact oxide while for TiNT a constant value is only reached after 21 days and for TiCO not even after 50 days. The constant decay observed for titania is presumably a result of the photocatalytic self-cleaning properties of $\mathrm{TiO}_{2}$, the oxide actively destroys attached SAM molecules when irradiated. Photodegradation is the process of material alteration in the presence of light and air, the degradation route involves oxidation and hydrolysis.[37] Such reactions are initiated upon photon absorption, energy transfer, molecular excitation and spontaneous radicalization in the presence of $\mathrm{O}_{2}$ and $\mathrm{H}_{2} \mathrm{O}{ }^{[37]}$ Titania reportedly has a bandgap of $(3.2 \mathrm{eV})$ and is widely accepted as an effective photocatalyst, implying that in the presence of light photolysis occurs.[38][39][40] On the contrary, zirconia has a phase dependent wide bandgap $(3.25-5.60 \mathrm{eV})$, amorphous zirconia is reported to show values greater than $4.2 \mathrm{eV}$, this is clearly larger than the excitation energy needed for titania.[17][41][42][43] Here, we could show that UVA light is sufficient for inducing degeneration of adsorbed functional SAMs on $\mathrm{TiO}_{2}$, i.e. the suitability of $\mathrm{TiO}_{2}$ coated with functional monolayers for indoor applications is also limited. Due to its wider bandgap, $\mathrm{ZrO}_{2}$ is catalytically 'inactive' under sunlight and does not exert active photodegradation, thus the hydrophobic SAM is able to remain intact on its surface.

It is interesting to note that photocatalytic degradation on $\mathrm{TiO}_{2}$ works best in the presence of ambient humidity and $\mathrm{H}_{2} \mathrm{O}$, as it is energetically favorable to form OH-radicals.[29] Thus, a 
greater deviation in stability of the hydrophobic coatings for $\mathrm{ZrO}_{2}$ and $\mathrm{TiO}_{2}$ is expected in the presence of water. In a further experimental setup, the respective sample sets were immersed in $\mathrm{H}_{2} \mathrm{O}$ in transparent Schott glass containers, under sunlight. Figure 4 (Wettability measurements of OPA modified $\mathrm{ZrO}_{2}$ nanotubes upon sunlight exposure in water-immersed condition (Contact angle versus Time)) depicts the trends observed in the presence of aqueous medium. Contact angles measured after 1 -day immersion and after 21 days amount to $\operatorname{ZrNT}\left(160^{\circ} \pm 2^{\circ} \rightarrow 130^{\circ} \pm 2\right)$, $\operatorname{TiNT}\left(<155^{\circ} \pm 2^{\circ} \rightarrow 112^{\circ} \pm 2^{\circ}\right), \operatorname{ZrCO}\left(125^{\circ} \pm 1^{\circ} \rightarrow 96^{\circ} \pm 1^{\circ}\right)$ and $\operatorname{TiCO}\left(95^{\circ} \pm 2^{\circ} \rightarrow 76^{\circ} \pm 2^{\circ}\right)$. It can be concluded that the stability of the hydrophobic coatings is also clearly enhanced for $\mathrm{ZrO}_{2}$ surfaces in aqueous environment. The initial packing density of the SAM is essential when considering the integrity of the composite system as it also contributes to improved hydrophobic behavior accompanied by the larger volumes of trapped-air within the nano-structured asperities. Surface hydration may affect the arrangement of the molecules within the monolayer and this, consequently, may influence the diffusion of oxidizing species. In the presence of water, additionally a hydroxyl mediated degradation has a higher possibility than when exposed only to air. An ideal case of full surface coverage prevents adsorption of water.[22][25] However, as concluded in the previous section, real systems have less than ideal coverage and as condensation reactions typically are reversible, a greater amount of exposed surface promotes the accessibility for further $\mathrm{H}_{2} \mathrm{O}$ molecules and the desorption of molecules. The stability of the OPA SAM in aqueous environment was furthermore evaluated by XPS. Figure 5 (Elution of hydrophobic OPA SAM from compact oxide substrates upon immersion in $\mathrm{H}_{2} \mathrm{O}$ after 7 days; $\mathrm{ZrO}_{2}$ and $\mathrm{TiO}_{2}$ ) depicts the elution of OPA-SAMs from $\mathrm{ZrCO}$ and TiCO samples over a 7-day period.

We conclude that Zirconia samples show a slower rate of destruction of the OPA-SAM on their surface and continue to remain hydrophobic at extended duration in water and under sunlight 
exposure, probably due to an improved packing density, higher desorption resistance and the lack of photocatalytic self-cleaning properties of the material.

The mechanical stability of the $\mathrm{OPA}-\mathrm{ZrO}_{2}$ coatings were additionally evaluated under a continuous jet of DI water for 1 min. Figure 6 (Hydrophobic film stability pre/post water flushing (Contact angle versus Time)) depicts an average percental loss (measured as a function of contact angle) of $(\sim 13 \pm 0.34 \%)$ in film coverage. It is noteworthy to mention that the contact angles represented in Figure 6, were possible to measure only along visible defects on the surfaces i.e. cracks/ scratches (probably created during experimental handling), (cf. Supporting Information, Figure S3). Furthermore, over $70 \%$ of water droplets continued to roll of the surface during the flushing experiment. Repetitions of the experiment did not lead to any further decrease of contact angles, indicating that only a fraction of the initially present OPA molecules is weakly bound to the $\mathrm{ZrO}_{2}$ surface. This experiment indicates that the observed contact angle decay on $\mathrm{ZrNT}$ during sunlight exposure in aqueous environment can be solely explained by desorbing OPA molecules from the $\mathrm{ZrO}_{2}$ surface.

To evaluate the role of 'active photodegradation' as a responsible source for the preferential OPASAM destruction on $\mathrm{TiO}_{2}$, a set of experiments was performed under harsh UV light exposure (400 W Xe lamp) on OPA-SAM coated $\mathrm{ZrO}_{2}$ and $\mathrm{TiO}_{2}$ samples. Figure 7. (Wettability measurements of OPA modified ZrNT and TiNT upon UV exposure in air (Contact angle versus Time)) and Figure 8. (XPS spectra: UV irradiation of OPA modified $\mathrm{ZrCO}$ and $\mathrm{TiCO}$ ) depict the trend in wettability and integrity of the SAM upon UV exposure. While the ZrNT samples show a hydrophobic surface over the entire duration of UV-light illumination, an accelerated decay of the OPA SAM is obvious on the $\mathrm{TiO}_{2}$ samples. A change to hydrophilic behavior is observed after $\sim 7$ min irradiation, which in turn is correlated to a significant loss of carbon signal from the 
material's surface as observed in XPS, indicating decomposition or desorption of the OPA monolayer. The inferior stability of hydrophobicity on $\mathrm{TiO}_{2}$ is predominantly attributed to the destruction of the OPA monolayer under active photocatalytic conditions. The expected lifetime of a superhydrophobic coating consequently is dependent on the substrate's bandgap and in conclusion, $\mathrm{ZrO}_{2}$ coatings are promising for application in superhydrophobic materials for both outdoor and indoor applications.

We summarize that the order of increasing SAM layer integrity on the substrate surface is such that $\mathrm{ZrO}_{2}>\mathrm{TiO}_{2}$ and anodized NT $>$ anodized $\mathrm{CO}$. Zirconia and titania samples show similar trends within their respective class of oxide structures (nanotubes and compact). The exact same translation within the sample types and classes suggest that the mechanism for SAM degradation consistently depends on the 'active' photocatalytic nature of the substrate, in combination with elution of weekly bound molecules.

\section{FIGURES/CAPTIONS}

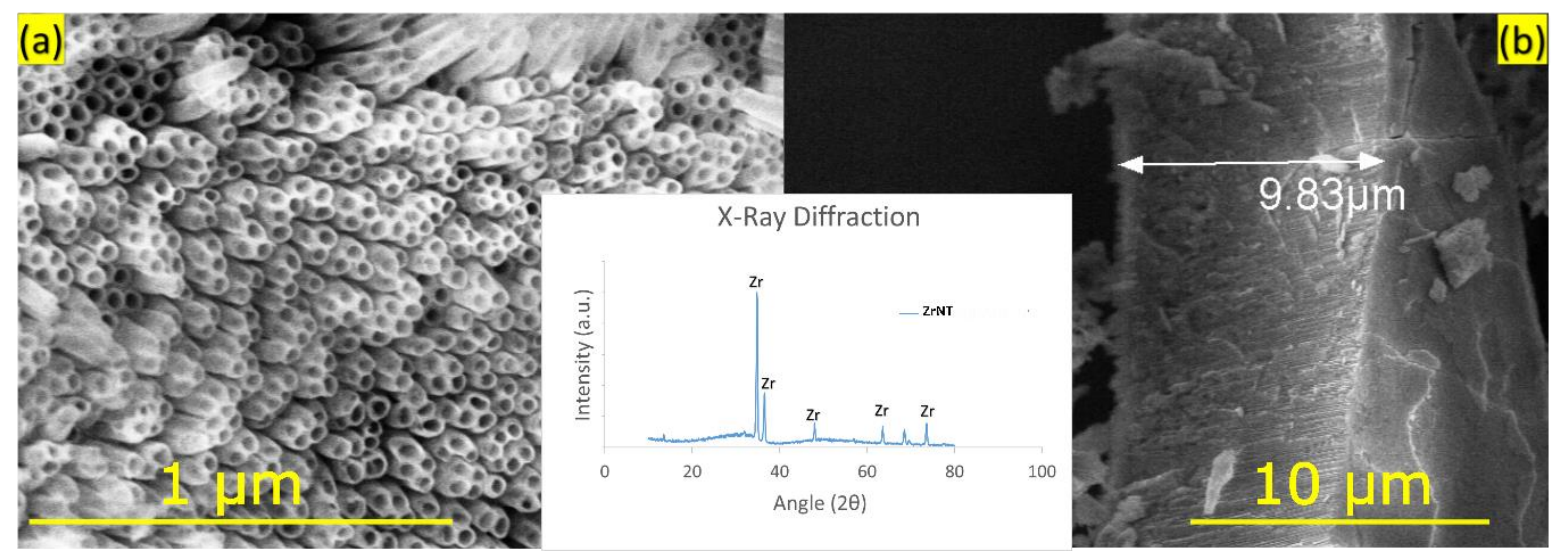

Figure 1. Anodization of $\mathrm{Zr}$ : SEM micrographs (a) anodized $\mathrm{ZrO}_{2}$ top, (b) anodized $\mathrm{ZrO}_{2}$ cross-section and $\mathrm{ZrO} \mathrm{XRD}_{2}$ (inset) 
(b)

\section{Comparison of surface modification}

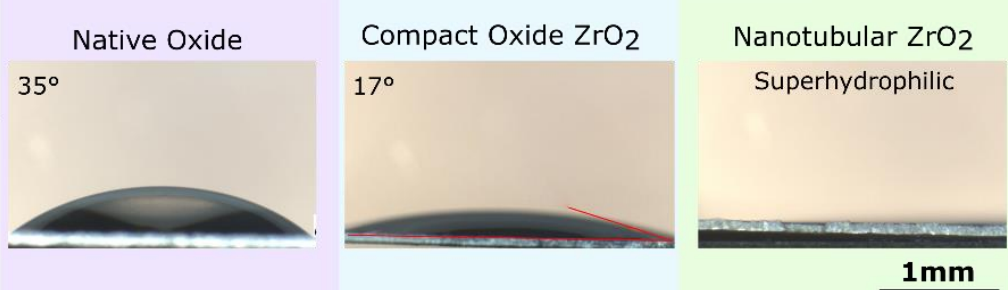

Samples modified with SAM layer

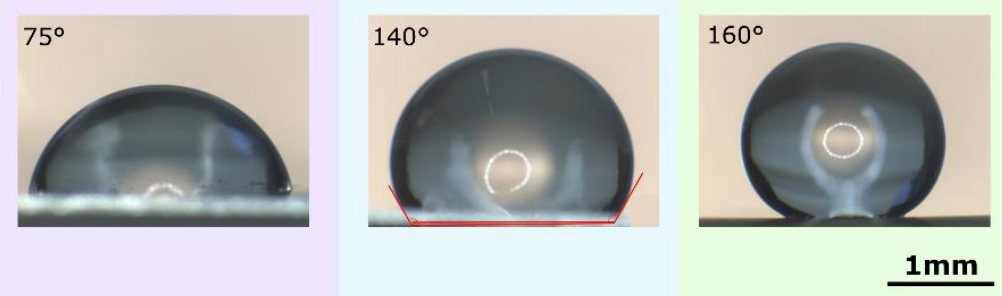

Figure 2. (a) Schematic - Cassie-Baxter model, (b) Comparison of surface hydrophobicity pre and post modification with ODPA SAMs on nanotubular $\mathrm{ZrO}_{2}$
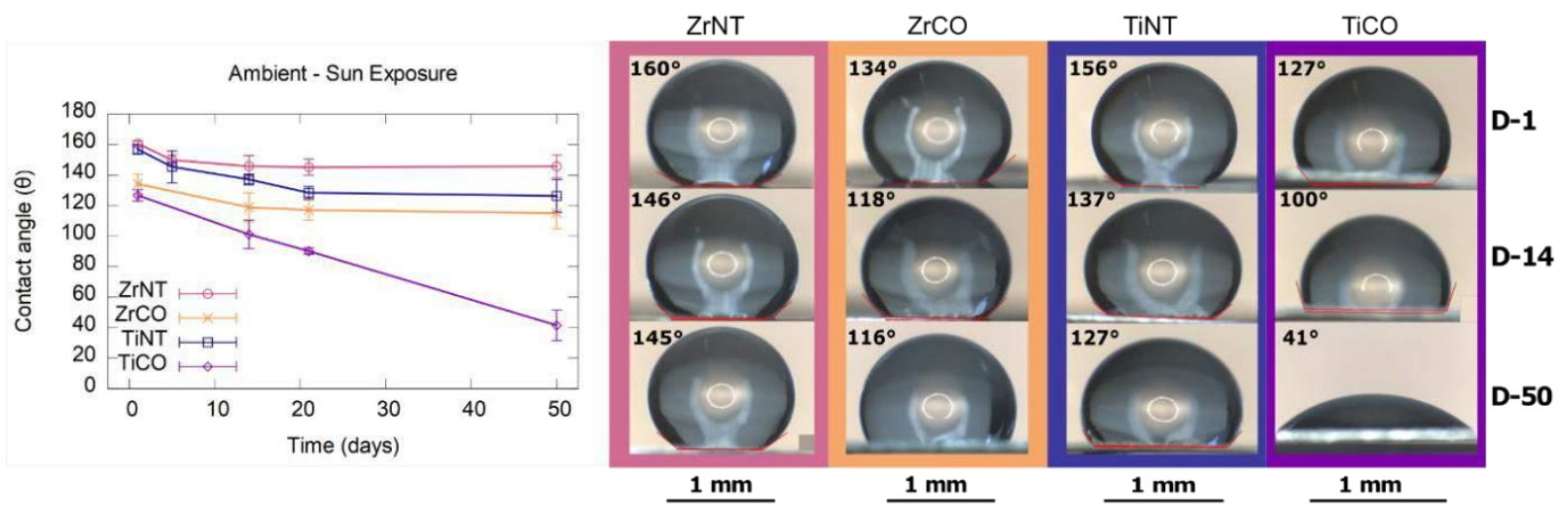

Figure 3. Wettability measurements of OPA modified oxide surfaces upon sunlight exposure in air (contact angle versus time)

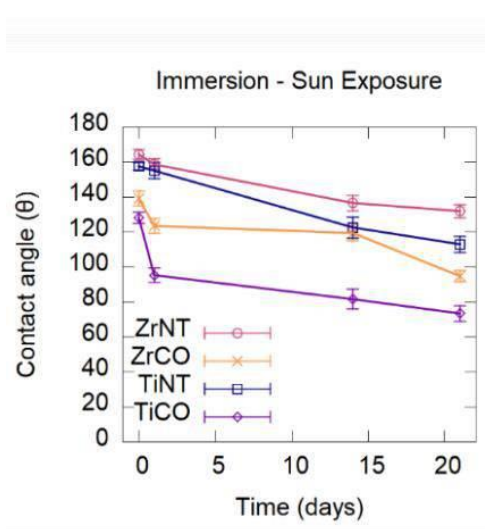

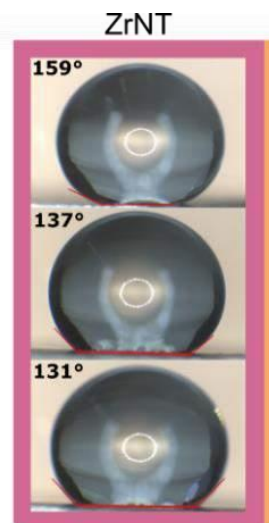

$1 \mathbf{~ m m}$

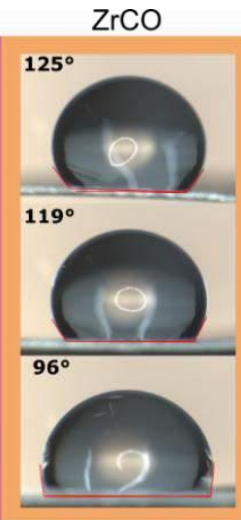

$1 \mathbf{~ m m}$

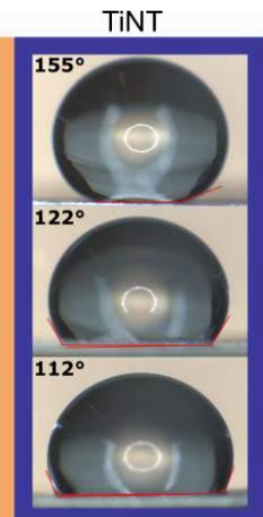

$1 \mathbf{~ m m}$

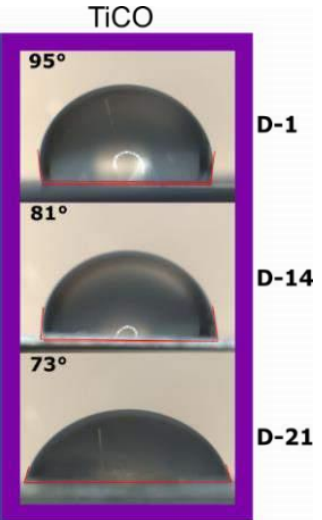

$\underline{\mathbf{~ m m}}$

Figure 4. Wettability measurements of OPA modified oxide surfaces upon sunlight exposure in water-immersed condition (contact angle versus time) 


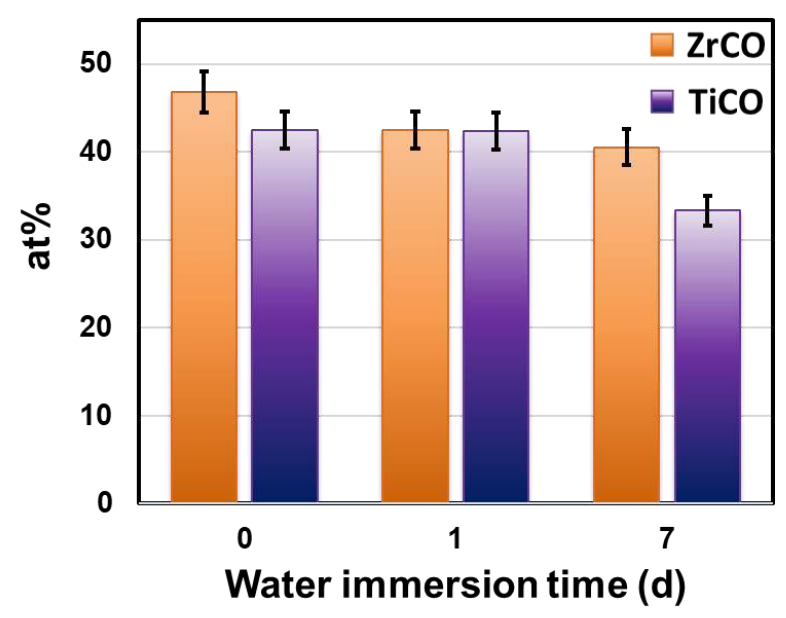

Figure 5. Elution of hydrophobic OPA SAM from compact oxide substrates upon immersion in $\mathrm{H}_{2} \mathrm{O}$ after up to 7 days; $\mathrm{Cls}$ on $\mathrm{ZrO}_{2}$ and $\mathrm{TiO}_{2}$ compact oxide (XPS).

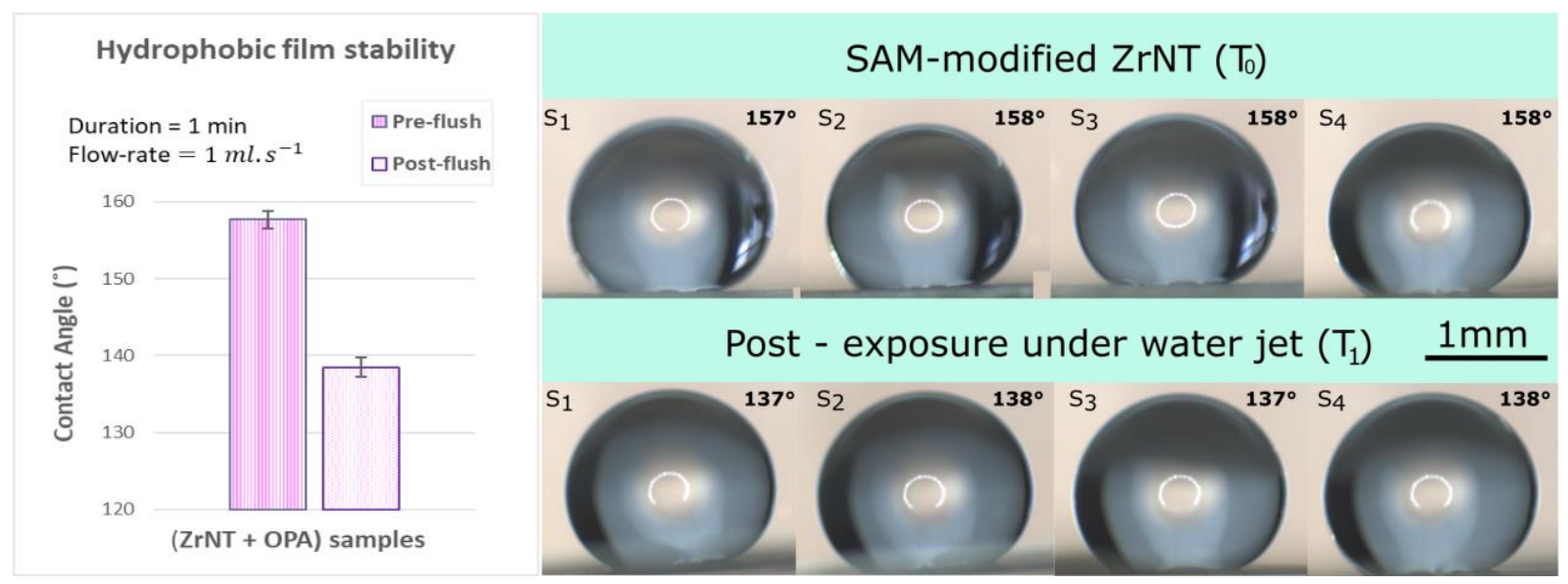

Figure 6. Hydrophobic film stability pre/post water flushing for 1 min on Zr-NT samples 

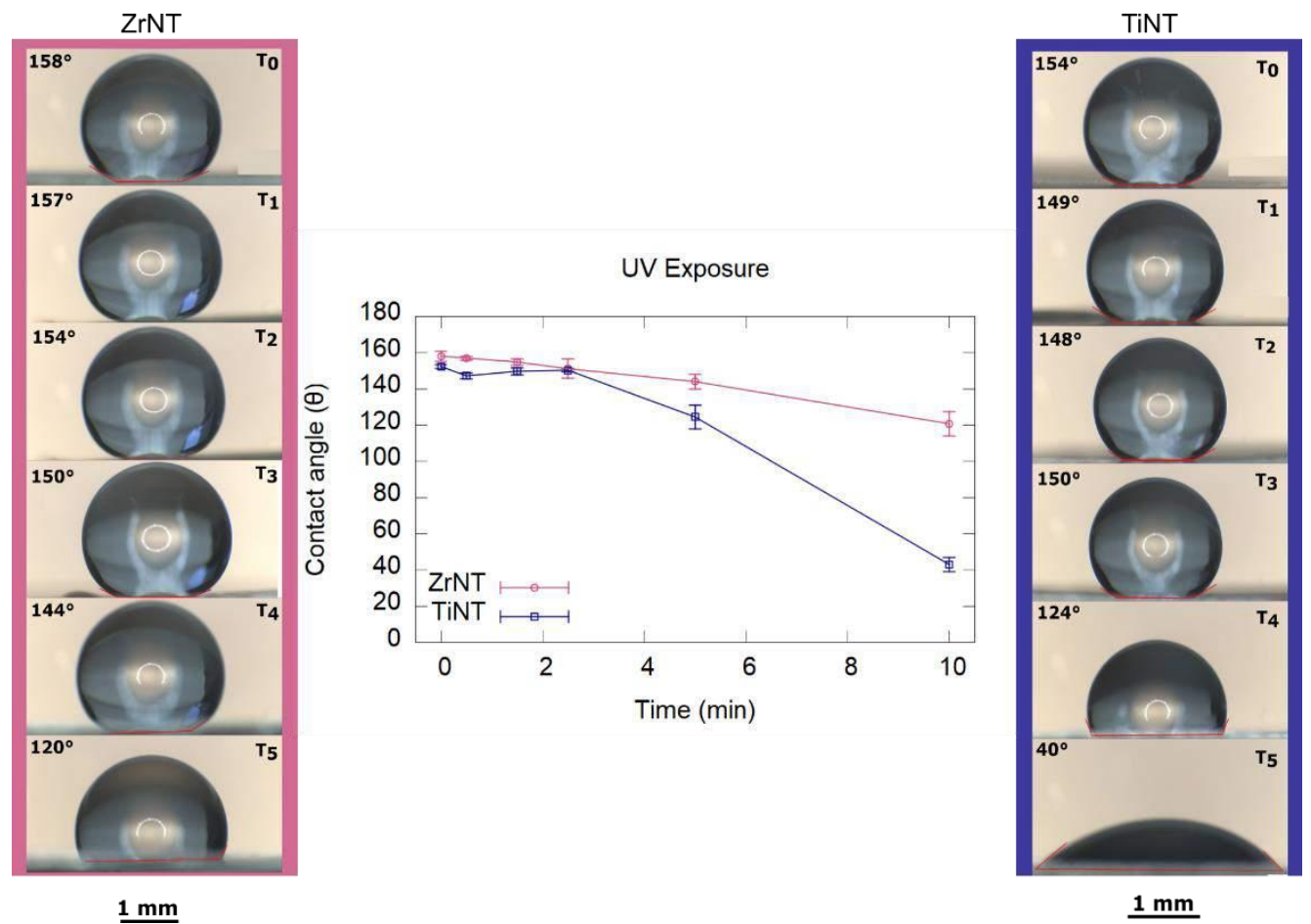

Figure 7. Wettability measurements of OPA modified ZrNT and TiNT upon UV exposure in air (contact angle versus time)

a)

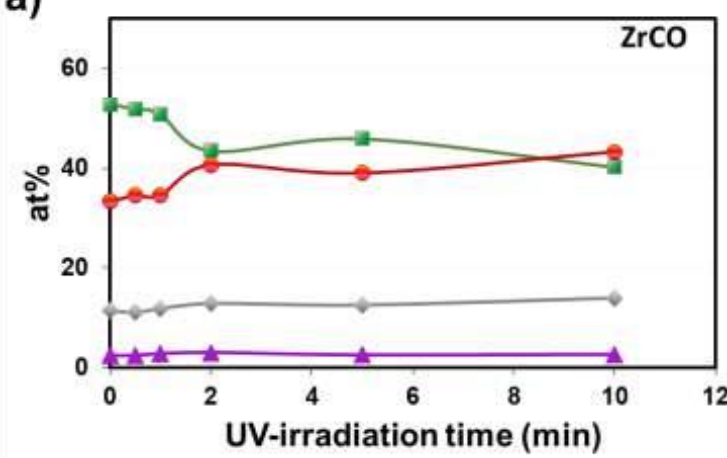

b)

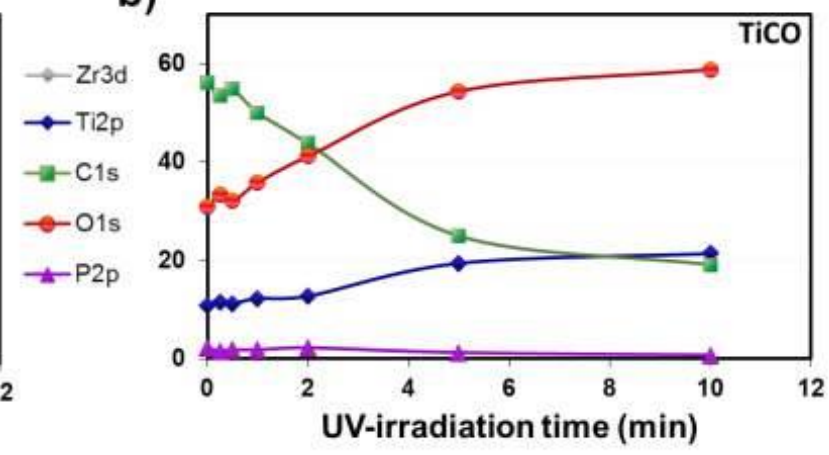

Figure 8. XPS spectra: UV irradiation of OPA modified $\mathrm{ZrCO}$ and TiCO

\section{Conclusion}

In this work, we synthesize $\mathrm{ZrO}_{2}$ nanostructures via single-step anodization process in the absence of hazardous HF acid containing etchants and render the surface superhydrophobic via OPA SAMs. The integrity of the OPA SAMs on $\mathrm{ZrO}_{2}$ nanotubes was extensively compared to $\mathrm{ZrO}_{2}$ compact oxide and also to the widely investigated $\mathrm{TiO}_{2}$ nanostructures. Therefore, the interaction 
and stability of OPA SAMs with oxide nanostructures of titania and zirconia under broad wavelength and UV-light exposure under different conditions were investigated. Wettability assessments confirm the relatively higher stability of zirconia-SAM composites for both classes of oxide-structures. It was found that a certain fraction of the OPA SAM can be removed by exposure to water. Investigation of the degradation behavior under UV-light exposure confirms the hypothesis that SAM degradation predominantly depends on the 'active' photocatalytic nature of the substrate. All results indicate towards the superiority of the zirconia-SAM based composites and such systems are promising candidates as stable optical coatings for outdoor applications.

\section{Experimental Section/Methods}

All chemicals were purchased by chemical suppliers and used without further purification. All organic solvents were of water-free grade.

4.1 Substrate preparation: $\mathrm{Zr}$ foil (99.2\% purity, Goodfellow UK, $0.125 \mathrm{~mm}$ thickness) and $\mathrm{Ti}$ foil (99.6\% purity, Advent Ltd., $0.1 \mathrm{~mm}$ thickness), were ultrasonically cleaned in ethanol and DI water and anodized using a Pt-sheet as the counter electrode. In order to synthesize compact oxide (CO) layers, the metal foils were anodized at $30 \mathrm{~V}$ respectively for $30 \mathrm{~min}$ in $1 \mathrm{M} \mathrm{H}_{2} \mathrm{SO}_{4}(\mathrm{Merck})$. For nanotubes (NT) Zr was anodized at 50V for $30 \mathrm{~min}$ and $\mathrm{Ti}$ at $50 \mathrm{~V}$ for 2 hours glycerol-based electrolyte containing 30vol\%formamide, 2wt\% $\mathrm{NH}_{4} \mathrm{~F}$ (Merck) and 2wt $\%$ distilled water respectively. Anodization was carried out using a high-voltage potentiostat (Jaissle IMP 88-200 PC), connected to a digital multimeter (Keithley 2000) interfaced to a computer. All samples were rinsed thoroughly with DI water after the anodization process and dried under a stream of $\mathrm{N}_{2}$.

4.2 SAM formation: Self-assembled monolayers of OPA (Merck) were prepared by immersion of as-prepared samples of zirconia and titania in solutions containing 10mM OPA in tetrahydrofuran (THF, Roth) for a duration of 6 hours at ambient conditions. Upon removal, the samples were rinsed in pure THF for 30 seconds and dried under a filtered nitrogen stream. 
SAM degradation: SAM coated oxides were subjected to indirect irradiation in air and underwater under sunlight for a period of $1,3,7,14,21$ and 50 days complimentary to tests under direct irradiation using a UV lamp (Heraeus Noblelight DQ 2523 mercury lamp with $400 \mathrm{~W}$ power output) for the duration of up to 10 minutes at a distance of $15 \mathrm{~cm}$ under the lamp source.

4.3 Mechanical stability: OPA-SAM coated ZrNT samples were subjected to a jet of DI water at a flow rate of $1 \mathrm{ml} / \mathrm{s}$ for a duration of 1 minute and dried under an $\mathrm{N}_{2}$ stream for $20 \mathrm{~s}$. Sessile water-droplet contact angle measurements were made before and after the flushing experiment. The percental loss of hydrophobicity was measured as a function of contact angle.

4.4 Characterization and surface analysis: The morphology of the anodized samples was evaluated by field emission scanning electron microscopy (FEI FEG Quanta 240 ESEM). Surface modification with OPA was evaluated using a ToF-SIMS V instrument (ION-TOF, Münster). Positive static SIMS measurements were performed on zirconia and titania compact oxide samples. XPS measurements were conducted on a high-resolution X-ray-photoelectron spectrometer (PHI 5600) using mono-chromated $\mathrm{Al} \mathrm{K} \square$ radiation (1486.6 eV) for excitation. The binding energy of the target elements was determined at a pass energy of $23.5 \mathrm{eV}$ and a total energy resolution of $<0.4 \mathrm{eV}$, and values were recorded every $0.1 \mathrm{eV}$ and at a take-off angle of $45^{\circ}$ with respect to the surface normal. Transmittance was recorded via transmission light microscopy using UV-LED light. In addition to these, Leica Suite Application was used to measure contact angles. $10 \mu \mathrm{l}$ DI water droplets were used to determine wetting behavior.

\section{Acknowledgements}

The authors acknowledge the DFG researcher group FOR 1878 and KI 2169/2-1 for funding. The authors would like to thank Prof. Patrik Schmuki, Dr. Alexander Tesler, Dr. Christian Pritzel, Dr. 
Maxime Hubert, Anja Friedrich, Anke Knoop and Ulrike Marten-Jahns for access to lab space, measurements, discussion and data evaluation

\section{Conflict of Interest}

The authors declare no conflict of interest.

\section{References}

[1] W. HUGHES, The Passivity of Metals, Nature. 106 (1921) 692-693. https://doi.org/10.1038/106692c0.

[2] A.S. Mogoda, Influence of some parameters on passivation of zirconium and the stability of the anodic oxide film, Corrosion. (1999). https://doi.org/10.5006/1.3284044.

[3] Y. Zhang, Z. Jiang, J. Huang, L.Y. Lim, W. Li, J. Deng, D. Gong, Y. Tang, Y. Lai, Z. Chen, Titanate and titania nanostructured materials for environmental and energy applications: A review, RSC Adv. (2015). https://doi.org/10.1039/c5ra11298b.

[4] E. Balaur, J.M. Macak, H. Tsuchiya, P. Schmuki, Wetting behaviour of layers of TiO2 nanotubes with different diameters, J. Mater. Chem. (2005). https://doi.org/10.1039/b509672c.

[5] F. Zhang, S. Chen, L. Dong, Y. Lei, T. Liu, Y. Yin, Preparation of superhydrophobic films on titanium as effective corrosion barriers, Appl. Surf. Sci. (2011).

https://doi.org/10.1016/j.apsusc.2010.10.027.

[6] Uhlig's Corrosion Handbook (2nd ed.), Aircr. Eng. Aerosp. Technol. (2000). https://doi.org/10.1108/aeat.2000.12772dae.001.

[7] A. V. Chadwick, Solid progress in ion conduction, Nature. 408 (2000) 925-926. https://doi.org/10.1038/35050201.

[8] C. Piconi, G. Maccauro, Zirconia as a ceramic biomaterial, Biomaterials. (1999). https://doi.org/10.1016/S0142-9612(98)00010-6.

[9] B.C.H. Steele, A. Heinzel, Materials for fuel-cell technologies, Nature. (2001). https://doi.org/10.1038/35104620.

[10] A.W. Amer, S.M. Mohamed, A.M. Hafez, S.Y. Alqaradawi, A.S. Aljaber, N.K. Allam, Self-assembled zirconia nanotube arrays: Fabrication mechanism, energy consideration and optical activity, RSC Adv. (2014). https://doi.org/10.1039/c4ra05115g.

[11] V. Grover, R. Shukla, A.K. Tyagi, Facile synthesis of ZrO2 powders: Control of morphology, Scr. Mater. (2007). https://doi.org/10.1016/j.scriptamat.2007.06.053.

[12] W. Li, H. Huang, H. Li, W. Zhang, H. Liu, Facile synthesis of pure monoclinic and tetragonal zirconia nanoparticles and their phase effects on the behavior of supported molybdena catalysts for methanol-selective oxidation, Langmuir. (2008). https://doi.org/10.1021/la800370r.

[13] J.P. Folkers, C.B. Gorman, P.E. Laibinis, S. Buchholz, G.M. Whitesides, R.G. Nuzzo, Self-Assembled 
Monolayers of Long-Chain Hydroxamic Acids on the Native Oxides of Metals, Langmuir. (1995). https://doi.org/10.1021/la00003a024.

[14] S.T. Yohe, Y.L. Colson, M.W. Grinstaff, Superhydrophobic materials for tunable drug release: Using displacement of air to control delivery rates, J. Am. Chem. Soc. (2012).

https://doi.org/10.1021/ja211148a.

[15] J.H. Choi, Y.M. Kim, Y.W. Park, T.H. Park, K.Y. Dong, B.K. Ju, Hydrophilic dots on hydrophobic nanopatterned surfaces as a flexible gas barrier, Langmuir. (2009).

https://doi.org/10.1021/la804325x.

[16] M. Zhou, X. Pang, L. Wei, K. Gao, Insitu grown superhydrophobic Zn-Al layered double hydroxides films on magnesium alloy to improve corrosion properties, Appl. Surf. Sci. (2015).

https://doi.org/10.1016/j.apsusc.2015.02.086.

[17] J.C. Garcia, L.M.R. Scolfaro, A.T. Lino, V.N. Freire, G.A. Farias, C.C. Silva, H.W.L. Alves, S.C.P. Rodrigues, E.F. Da Silva, Structural, electronic, and optical properties of ZrO2 from ab initio calculations, J. Appl. Phys. (2006). https://doi.org/10.1063/1.2386967.

[18] P.H. Mutin, G. Guerrero, A. Vioux, Hybrid materials from organophosphorus coupling molecules, J. Mater. Chem. (2005). https://doi.org/10.1039/b505422b.

[19] F. Schreiber, Structure and growth of self-assembling monolayers, Prog. Surf. Sci. (2000). https://doi.org/10.1016/S0079-6816(00)00024-1.

[20] R.K. Smith, P.A. Lewis, P.S. Weiss, Patterning self-assembled monolayers, Prog. Surf. Sci. (2004). https://doi.org/10.1016/j.progsurf.2003.12.001.

[21] A. Ulman, Formation and structure of self-assembled monolayers, Chem. Rev. (1996). https://doi.org/10.1021/cr9502357.

[22] M.S. Killian, Organic Modification of TiO2 and other Metal Oxides with SAMs and Proteins - a Surface Analytical Investigation, Tech. Fak. (2013).

[23] B. Adolphi, E. Jähne, G. Busch, X. Cai, Characterization of the adsorption of $\omega$-(thiophene-3-yl alkyl) phosphonic acid on metal oxides with AR-XPS, in: Anal. Bioanal. Chem., 2004. https://doi.org/10.1007/s00216-004-2634-x.

[24] W. Gao, L. Dickinson, C. Grozinger, F.G. Morin, L. Reven, Self-assembled monolayers of alkylphosphonic acids on metal oxides, Langmuir. (1996). https://doi.org/10.1021/la9607621.

[25] M.C.O. Monteiro, G. Cha, P. Schmuki, M.S. Killian, Metal-Phosphate Bilayers for Anatase Surface Modification, ACS Appl. Mater. Interfaces. (2018). https://doi.org/10.1021/acsami.7b16069.

[26] E.S. Gawalt, G. Lu, S.L. Bernasek, J. Schwartz, Enhanced bonding of alkanephosphonic acids to oxidized titanium using surface-bound alkoxyzirconium complex interfaces, Langmuir. (1999). https://doi.org/10.1021/la990906m.

[27] D.A. Chang, P. Lin, T.Y. Tseng, Optical properties of ZrTiO4 films grown by radio-frequency magnetron sputtering, J. Appl. Phys. 77 (1995) 4445-4451. https://doi.org/10.1063/1.359472.

[28] S. Berger, J. Faltenbacher, S. Bauer, P. Schmuki, Enhanced self-ordering of anodic ZrO2 nanotubes in inorganic and organic electrolytes using two-step anodization, Phys. Status Solidi - Rapid Res. Lett. (2008). https://doi.org/10.1002/pssr.200802019. 
[29] Y.Y. Song, F. Schmidt-Stein, S. Bauer, P. Schmuki, Amphiphilic TiO2 nanotube arrays: An actively controllable drug delivery system, J. Am. Chem. Soc. (2009). https://doi.org/10.1021/ja810130h.

[30] M.S. Killian, J.F. Gnichwitz, A. Hirsch, P. Schmuki, J. Kunze, ToF-SIMS and XPS studies of the adsorption characteristics of a Zn-porphyrin on TiO2, Langmuir. 26 (2010) 3531-3538. https://doi.org/10.1021/la9032139.

[31] P.R. Rauta, P. Manivasakan, V. Rajendran, B.B. Sahu, B.K. Panda, P. Mohapatra, Phase transformation of ZrO 2 nanoparticles produced from zircon, Phase Transitions. (2012). https://doi.org/10.1080/01411594.2011.619698.

[32] J. Čyviene, J. Dudonis, Zr, ZrN and ZY/Al thin films deposition using arc evaporation and annealing, Acta Phys. Pol. A. 114 (2008) 769-777. https://doi.org/10.12693/APhysPolA.114.769.

[33] A.B.D. Cassie, S. Baxter, Wettability of porous surfaces, Trans. Faraday Soc. (1944). https://doi.org/10.1039/tf9444000546.

[34] S.N.V. Raghu, M. S. Killian, "Wetting behaviour of Zirconia nanotubes" . Submitted

[35] J.D. Haigh, The sun and the earth's climate, Living Rev. Sol. Phys. (2005).

[36] M. Wacker, M.F. Holick, Sunlight and Vitamin D: A global perspective for health, Dermatoendocrinol. (2013). https://doi.org/10.4161/derm.24494.

[37] H.D. Burrows, M. Canle L, J.A. Santaballa, S. Steenken, Reaction pathways and mechanisms of photodegradation of pesticides, J. Photochem. Photobiol. B Biol. (2002). https://doi.org/10.1016/S1011-1344(02)00277-4.

[38] Y. Wang, N. Herron, Nanometer-sized semiconductor clusters: Materials synthesis, quantum size effects, and photophysical properties, J. Phys. Chem. (1991). https://doi.org/10.1021/j100155a009.

[39] K.M. Reddy, S. V. Manorama, A.R. Reddy, Bandgap studies on anatase titanium dioxide nanoparticles, Mater. Chem. Phys. (2003). https://doi.org/10.1016/S0254-0584(02)00343-7.

[40] B.D. Cullity, J.W. Weymouth, Elements of X-Ray Diffraction, Am. J. Phys. (1957). https://doi.org/10.1119/1.1934486.

[41] S. Bhaskar, E.W. Awin, K.C.H. Kumar, A. Lale, S. Bernard, R. Kumar, Design of nanoscaled heterojunctions in precursor-derived t-ZrO2/SiOC(N) nanocomposites: Transgressing the boundaries of catalytic activity from UV to visible light, Sci. Rep. 10 (2020) 1-13. https://doi.org/10.1038/s41598-019-57394-8.

[42] S. Heiroth, R. Ghisleni, T. Lippert, J. Michler, A. Wokaun, Optical and mechanical properties of amorphous and crystalline yttria-stabilized zirconia thin films prepared by pulsed laser deposition, Acta Mater. (2011). https://doi.org/10.1016/j.actamat.2010.12.029.

[43] H. Haick, Y. Paz, Remote photocatalytic activity as probed by measuring the degradation of selfassembled monolayers anchored near microdomains of titanium dioxide, J. Phys. Chem. B. (2001). https://doi.org/10.1021/jp0037807. 


\section{SUPPORTING INFROMATION}

\section{Zirconia nanotube coatings - UV-resistant superhydrophobic surfaces}

Swathi Naidu Vakamulla Raghu, Khajidkhand Chuluunbandi, Manuela Sonja Killian*

\section{S1: Anodic oxide structures}

Anodization offers the possibility of tuning the type of anodic oxide produced. It results in an improved oxide quality that consequently affect the extent of surface functionalization. Different surface structures elicit different degrees of wettability and we compare flat oxides and nanotubular oxides in our experiments. In order to synthesize flat / compact oxide (CO) layers, the metal foils ( $\mathrm{Zr}$ and $\mathrm{Ti}$ ) were anodized at $30 \mathrm{~V}$ for $30 \mathrm{~min}$ in $1 \mathrm{M} \mathrm{H}_{2} \mathrm{SO}_{4}$ (Merck), respectively. Figure $\mathrm{S} 1$ represents the SEM micrographs - Top view: (a) $\mathrm{ZrO}_{2}-$ Compact Oxide, (b) $\mathrm{TiO}_{2}-\mathrm{Compact}$ Oxide)

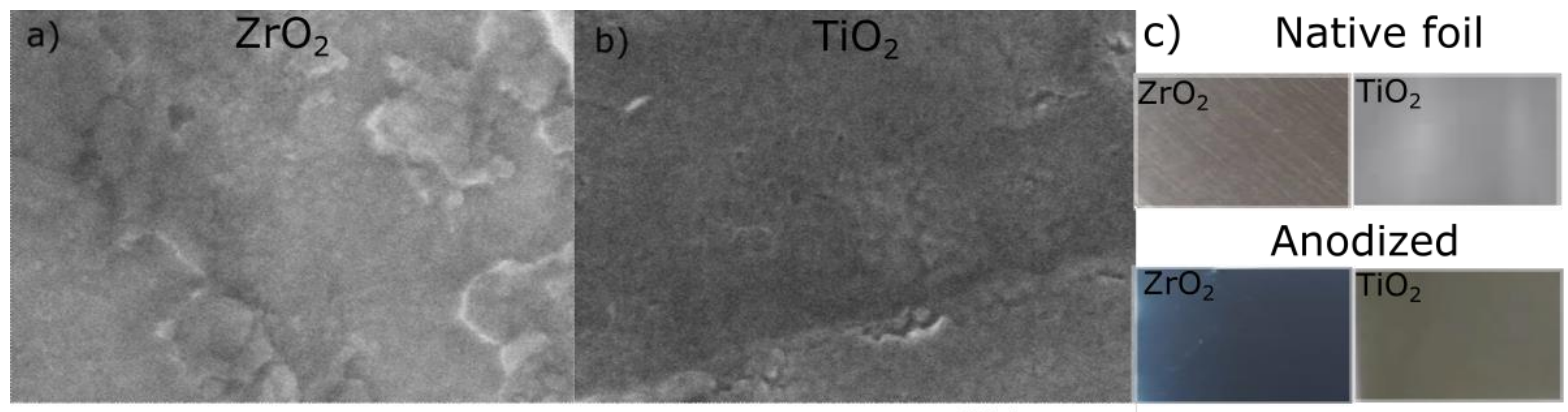

\section{$500 \mathrm{~nm}$}

Figure S1. Anodic oxide structures: SEM micrographs - Top view: (a) $\mathrm{ZrO}_{2}$ - Compact Oxide, (b) TiO2- Compact Oxide, c) optical photographs of the metal foil surface prior and post anodization.

The SEM images clearly show a non-porous surface after anodization of Zr-CO and Ti-CO.

Optically, a clear change in material can be deduced from a color change from metallic gray to blue, indicating an anodic oxide thickness of $\sim 50 \mathrm{~nm}$.

\section{S2: Compositional characterization}


Time-of-flight secondary ion mass spectrometry (ToF-SIMS) was used to evaluate the surface composition of the OPA modified $\mathrm{Zr}$ and $\mathrm{Ti}$ oxide substrates, respectively. $\mathrm{C}_{18} \mathrm{H}_{38} \mathrm{PO}_{3}{ }^{-}$was determined as characteristic fragment for the OPA molecules.

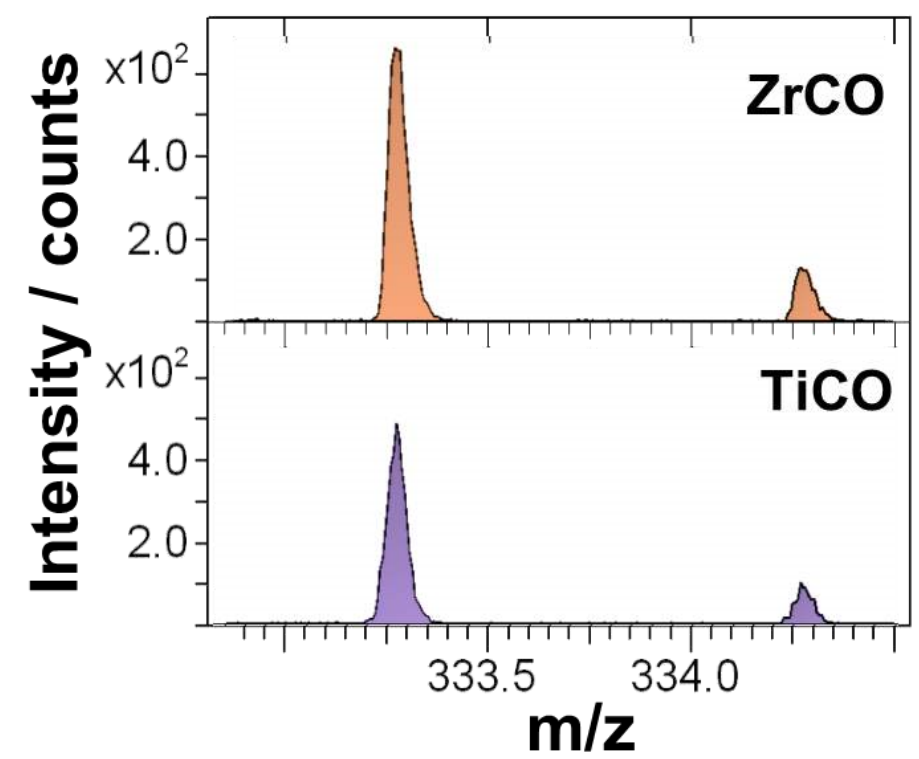

Figure S2. Compositional characterization- (Quasi-) molecular or characteristic fragments of the adsorbed OPA-coated compact oxide $\left(\mathrm{M}-\mathrm{H}^{-}\right)$on compact $\mathrm{ZrO}_{2}$ and $\mathrm{TiO}_{2}$

The quasi-molecular signals of OPA $\left(\mathrm{m} / \mathrm{z}=333.29, \mathrm{C}_{18} \mathrm{H}_{38} \mathrm{PO}^{-}, \mathrm{M}^{-} \mathrm{H}^{-}\right)$can be clearly detected in ToF-SIMS measurements (Figure S3), proving the presence of the molecule on the oxide surface.

\section{S3: Wettability of functionalized ZrNT and the influence of surface inhomogeneities}

ZrNT surfaces continue to remain hydrophobic for a prolonged duration when subjected to various experimental conditions and relatively small changes were recorded during the contact angle measurements. This variation in hydrophobicity is attributed to the loss of OPA coverage from the ZrNT surfaces. Ideally, a superhydrophobic coating will have uniform coverage when the underlying surface is homogenous. However, as in the case of these in-situ experiments, handling and experimental procedures result in exposing the underlying substrate as a result of surface 
scratches, localized film-flaking and mechanical stresses while cutting and shaping of the test specimens. Thereby, increasing localized surface energy and promoting droplet wetting around such defects. Figure S3 (a) shows a representative image of a freshly anodized Zirconia foil that is scratch free and shows a homogeneous surface, water droplets continue to roll-off the defect free surface. Figure S3 (b) shows a foil that underwent mechanical stress induced by cutting and accompanied bending of the foils prior to various test conditions. This surface consists of topical scratches and film-flaking in certain regions, consequently exposing the underlying substrate and promoting droplet adherence on such visibly defective regions.

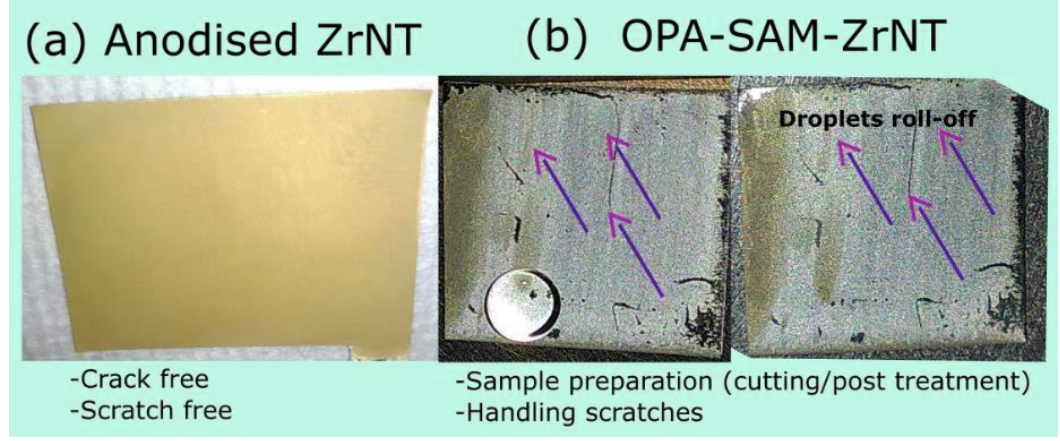

Figure S3. Wettability of functionalized ZrNT and the influence of surface inhomogeneities

Droplets, however, continue to roll off the surface in any mechanically undamaged region of the sample surface. The used foils have a thickness of $0.125 \mathrm{~mm}$, making such defects less likely if the nanostructures are grown on a more rigid substrate.

\section{S4: Titania nanotube synthesis}

Titania nanotubes (TiNT) were synthesized at 50V for 2 hours in a glycerol-based electrolyte containing $30 \%$ formamide, $2 \mathrm{wt} \% \mathrm{NH}_{4} \mathrm{~F}$ (Merck) and distilled water. These parameters were chosen in order to get structures with open pores devoid of any influencing initiation layer. This surface treatment was best suited for functionalization, resulting in super-hydrophobic contact 
angles $\left(159^{\circ} \pm 2^{\circ}\right)$ that were comparable to $\mathrm{ZrNT}$ samples. The reported structures are depicted in Figure S5.

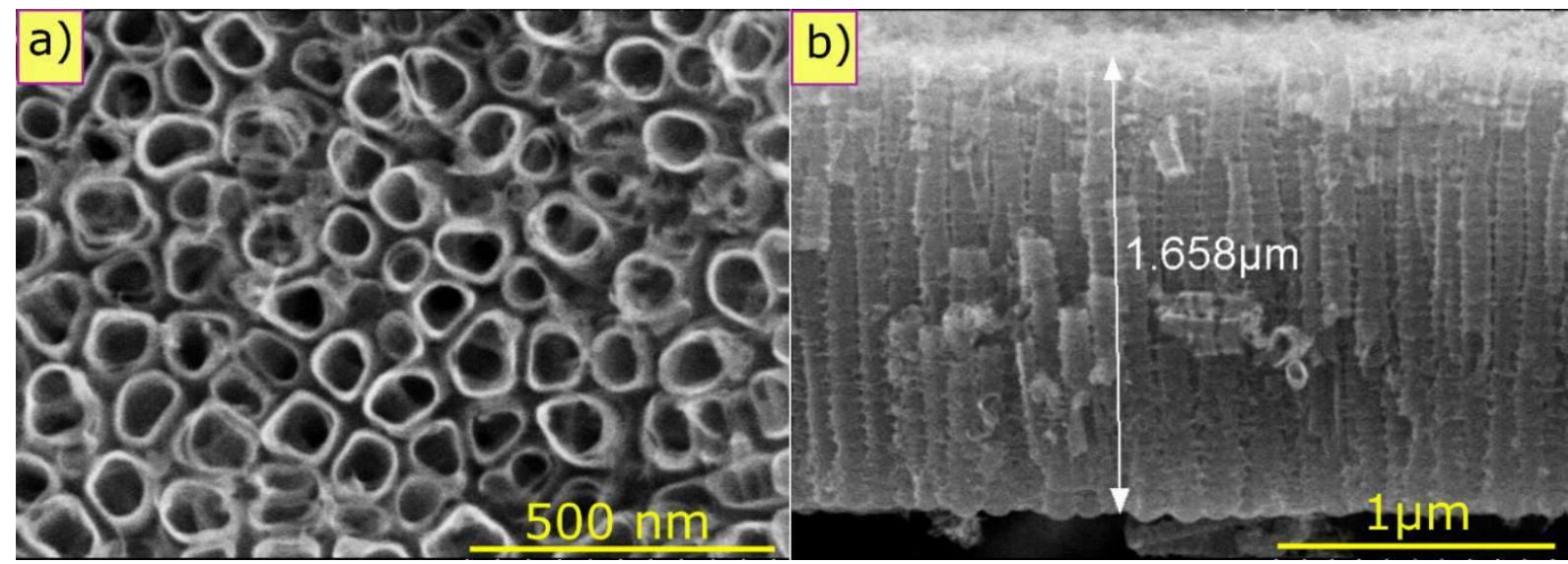

Figure S4. Titania nanotube synthesis: SEM micrographs - (a)TiO2-NT top, (b) TiO2-NTcross-section

It is interesting to mention, that the ZrNT show a comparable or even improved hydrophobicity, even though they show a smaller tube diameter than the $\mathrm{TiO}_{2}$ nanotubes. Smaller diameters have been reported to yield in lower hydrophobicity for OPA modified TiNTs previously.[S1]

\section{S5: Optical transparency of $\mathrm{Zr}$ coatings}

Samples types; ZrNT film and ZrNT+OPA were prepared as described in the main manuscript in the experimental section. These test specimens were then subjected to direct illumination under 12V-100W, HAL-L lamp (Olympus) eliciting a spectrum of white light under the optical microscope. Time of exposure and sample measurements were recorded on the same day under identical conditions. 
(a) Transparent tape

(b) $\operatorname{ZrNT}(\mathrm{t} \leq 3 \mu \mathrm{m})$

(c) ZrNT+OPA)

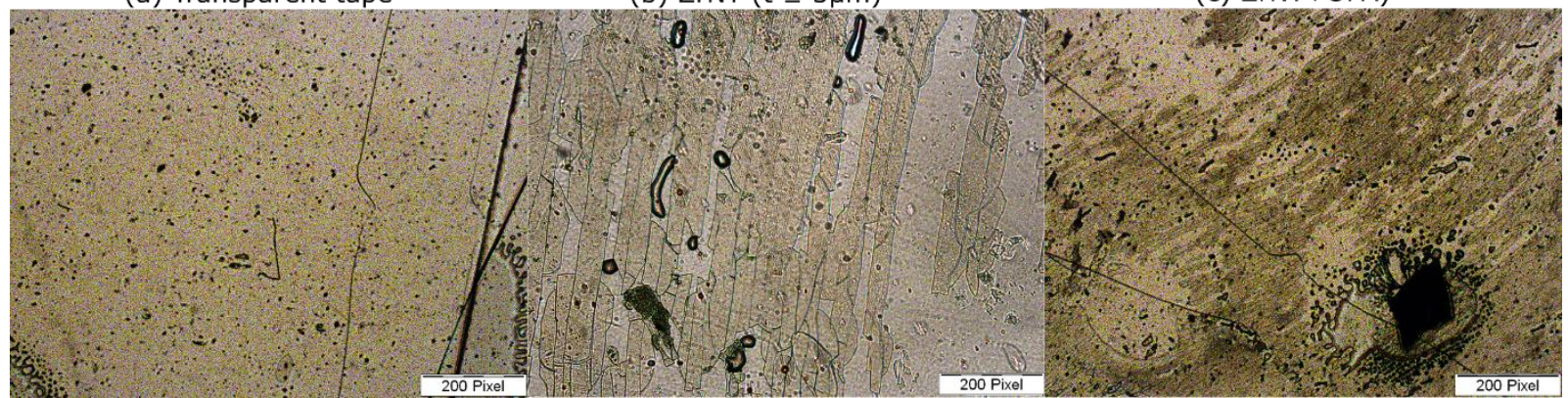

Figure S5. Optical transparency of Zr coatings

\section{Optical transmittance in $\mathrm{Zr}$ coatings}

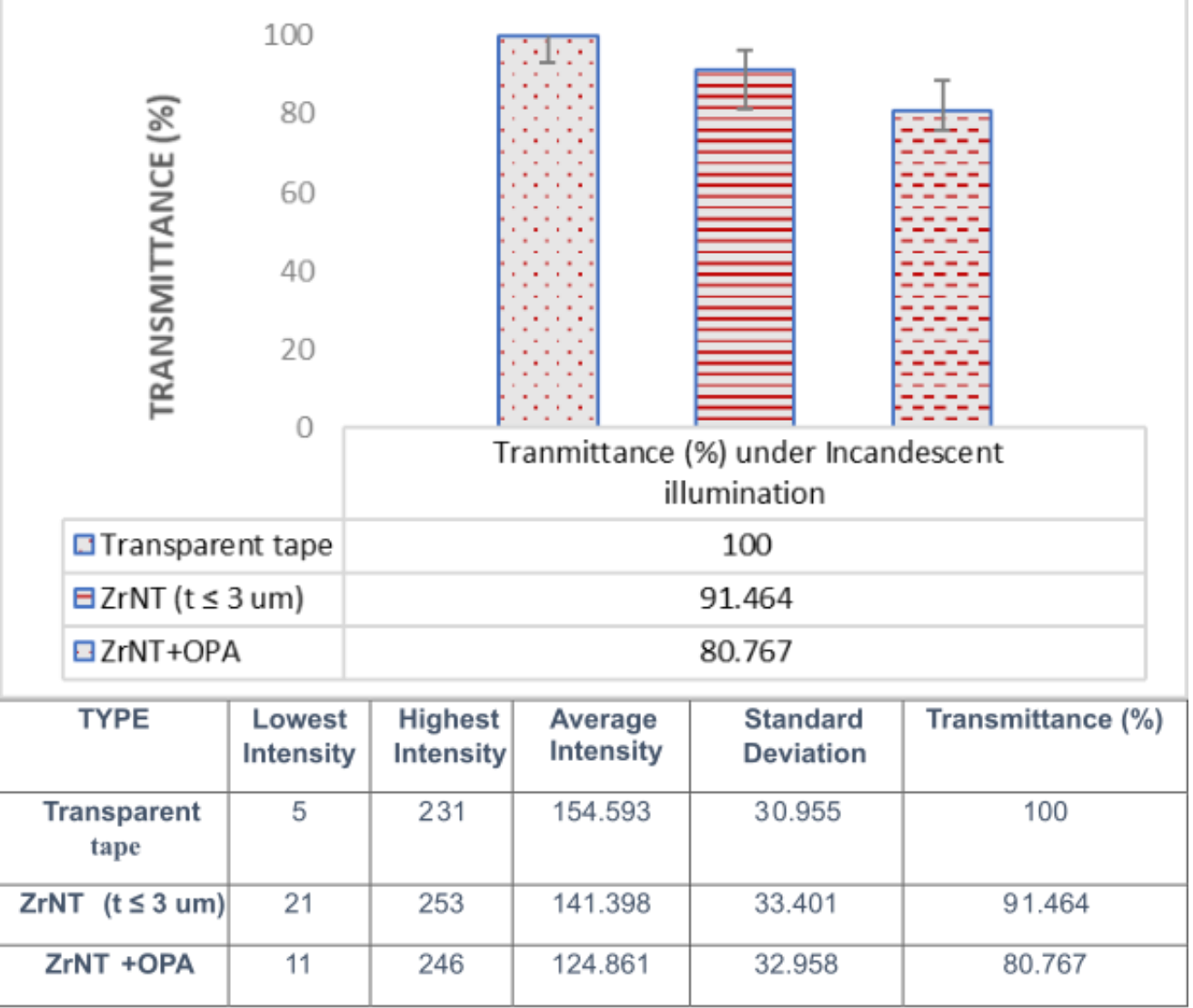

Table S5. Optical transmittance in $\mathrm{ZrO}_{2}$ coatings

Figure S5 shows SEM micrographs under direct illumination and Table S5. (Optical transmittance in $\mathrm{Zr}$ coatings), corresponds to the summary of the values obtained under the direct transmittance 
setup. ZrNT, when coated with OPA registered $10 \%$ decrease in transmittance. We conclude that ZrNT coatings remain transparent for $80 \%$.

\section{REFERENCES}

[S1] E. Balaur, J.M. Macak, H. Tsuchiya, P. Schmuki, Wetting behaviour of layers of TiO2 nanotubes with different diameters, J. Mater. Chem. (2005). https://doi.org/10.1039/b509672c 